\title{
Avoidable childhood death: A case of mismanagement and inappropriate medication use
}

\author{
Taha Nazir*, Syed Muzzamil Masood Zaidi, Ashfaq Ahmad and Tahir Aqeel \\ The University of Lahore - Islamabad Campus, 24 Jinnah Avenue, Islamabad, Pakistan.
}

Accepted 25 March, 2011

\begin{abstract}
Rational drug usage, clinical regulations and pharmaceutical care are important features of health practice. Thus; we have aimed case report to elaborate the clinical pharmaceutical services. A 3 year old girl, was presented in a hospital with minor burn that happened by spilt hot water on her wrist. She was in severe pain. The emergency ward staff applied an ointment. The doctor instructed injection Dormicum two times with short gape and then 3rd injection of Pavulon (Pancuronium). Patient went silent and started losing consciousness and eventually passed away. In view of the above facts and circumstances the inquiry board and judiciary took action against the negligence, mishandling. While; going through the investigation the inquiry board did not bothered the channel through which this injection came without proper check that is therapeutical drug monitoring, prescription reviewing, biosafety and pharmaceutical evaluation. Furthermore, it is not a single death but representation of so many casualties because of the wrong medications. The medial practice needs some more legal, professional and principled restrictions to make sure the safe and correct therapy plans. The clinical legislation, drug rules and medical practice seriously need the attention of judiciary, society and leadership to assure the safety of precious live.
\end{abstract}

Key words: Wrong medication, medical malpractice, professional negligence, pharmaceutical services, Suomoto notice of chief justice of high court.

\section{INTRODUCTION}

Health care providers are said to be negligent if they fail to provide the standard care that an expert would give in similar circumstances. If the negligence resulted in injuries or illnesses the health care provider may be liable. If the doctor was clearly wrong, patient can sue him/ her for malpractice (CBA, 2010). Healthcare professionals are expected to be current in their knowledge of disease diagnoses and treatment to meet a reasonable standard of treatment; depending upon the available facilities for optimum patient's care. The health care professional of the developing part of the worlds may be partially exempted because of the compulsion of adopting the crude methods of care to save the patient's life. According to medical malpractice law, a doctor of

${ }^{*}$ Corresponding author. E-mail: tahanazir@yahoo.com, taha.nazir@uos.edu.pk. Tel: +92 51282 9162-64, 282 9697-8. Fax: +92512829238. advance counties owes a duty to conduct his practice like a prudent and diligent physician (Medical Malpractice, 2010). Standards and regulations for medical malpractice may differ from one country to other and with the jurisdiction within the countries. Medical professionals of developed nations are especially required to maintain professional liability insurance to offset the risk and costs of lawsuits based on local medical malpractice (BBC News, 2010).

This report therefore aimed to look at the reasons of clinical errors in developing part of the world. It is not professional revenge, unenthusiastic critics or commercially biased outlook but an optimistic report to encourage the accomplishment of health standards and rational drug usage. Therapeutical drug monitoring, biosafety, pharmaceutical care, prescription review and clinical services carry their meanings in health science. We have to assign the responsibilities to other health caring professionals especially the pharmacists to avoid irrational drug usage. 


\section{CASE REPORT}

A 3 year old girl presented to the pediatric emergency unit of the hospital over a year ago, very early in the morning, with a very small burn wound on her left hand, following an accident spilling of a hot water to the wrist. The accident was sustained while playing with her friends. Except for her severe pains, she was otherwise normal. She was irritable with pain. CMO attended her and advised Xylocain Gel and Dermazine Ointment for local application. But the child remained in pain. The resident medical officer surgery was called, he prescribed Syp. Brufen and Syp. Phenergan. There were no improvement, pediatric consultation was sought and called in the emergency who advised injection Dormicum, Which was administered intravenously. Her father stated that when nurse walked into the room that doctor had obviously been asleep and had just been woken up. The doctor instructed nurse to give injection Dormicum. Ten minutes later doctor instructed the nurse to repeat the injection dose. She continued to cry because of the pain, the nurse called the doctor on duty. Afterward; the sleepy doctor went to the pharmacy, bought some stuff and asked father to go and pay at the pharmacy. He instructed the nurse to inject the 3rd injection Pavulon that he bought from the hospital's pharmacy himself. This injection Pavulon was administered in presence of the doctor and just after the fifteen minutes of previous injection Dormicum. This was the moment when the little baby went silent and started losing consciousness. She went into respiratory arrest and cardiac failure within few minutes and could not be revived. Just before passing out totally, she started calling the name of her father. Her vision became blurred. The last words she ever spoke were; Dad! What is this, Dad! Who they are, Dad! Who is that coming? Father asked the doctor about this dreadful situation, he again assured that she was fine and left the room. Father examined the daughter himself and did not find the pulse and respiration. He immediately informed the nurse. She called the doctor again. Who also not felt heart beat on the monitor. He gave the explanation that the monitor was intended for adult, therefore it could not detect baby's heart beat. Some other on duty doctors joined as well. They connected ECG machine, but that too obtain straight line. All the doctors on the scene conferred one another and incessantly ignored the parent's repeated query of what was happening to daughter. They started cardiopulmonary resuscitation (CPR). The father smelled out that the situation is quiet serious and some thing happened horribly wrong. The doctors however, kept reassuring them that she was fine. Another $30 \mathrm{~min}$ or so passed in this torture and confusion. Father asked if she was ok, why there was no pulse, on the ECG, no heartbeat and why were they giving her CPR, if she was ok then why?

Eventually; one of the doctor talked to the father that she was having difficulty breathing and they did not have a baby ventilator, therefore take her to some other hospital before aggravation of her condition. He requested the ambulance because she was connected with machines. Doctor said ambulance was not available and if he still wanted one then waits for half an hour. The patient baby was not breathing and doctors wanted him to wait for half an hour. Father decided to take his dying daughter in his own car. He pleaded for doctor to accompany to explain what exactly her condition was. They asked a ward boy to go along. He requested the list of medications, copy of ECG report and clinical findings. Nothing was given. It took $15 \mathrm{~min}$ to reach next hospital. Where they were told that this 3 year old baby, their innocent child, the light of life, reason to live has already passed away. Father returned back to first hospital to obtain the treatment plan, clinical test reports, therapeutical profile and detail of medication given, which were again refused to be provided. At that moment father decided to strive for justice and bring the culprits to court. $\mathrm{He}$ only wanted to avoid loss of precious lives of others patients in future. He also stated that he was not the only one who has had his life shattered by this institution. There are several other similar events dumped in this hospital. He can explore such cases to expose the clinical malpractice, professional negligence and therapeutical blunders.

\section{DISCUSSION}

On November 29, 2009 at 3 am in the morning a 3 year old girl has spilt hot water on her wrist while playing with her friends. Parent immediately took her to near private hospital. The public sector government hospitals are generally not supposed to provide the standard health care services in Pakistan. This case turn out to be publicly illustrious when the Honorable Chief Justice of the High Court, took the suo-moto notice of the news item that appeared in the local news paper regarding the death three years old girl. The inquiry report, compiled by the board, comprised local experts and has stated that, the patient was presented to the emergency department of hospital with a scald burn on her left hand. She was irritable with pain, CMO attended her and advised Xylocain Gel and Dermazine ointment to be applied locally. The child remained in pain. The resident medical officer surgery was called. He prescribed Syp. Brufen and Syp. Phenergan. There were no improvement, pediatric consultation was sought and called in the emergency. He advised that Dormicum injection should be administered intravenously. Since there was no relief for the pain, he then advised that Pavulon injection should be administered by a nurse in his presence. After some time, the patient went into respiratory arrest.

The enquiry board reported that the treatment was taken properly by the hospital; the right medications were given with the exception of the Pavulon injection. The 
pediatric consultation who prescribes this injection stated that he has advised it as a sedative drug just to relax the patient from unbearable pain as well as to lessen the anxiety of her family members. Thus; the board members were afraid that the concept of pediatric consultation in respect of Pavulon injection is not correct. His action and suggestion in the above mentioned case is apparently an error and misconception. Therefore; the committee held pediatric consultation responsible for negligence, mishandling of the patient and failure to provide standard treatment. He did not have sufficient professional exposure and therapeutical skills regarding the drugs and medications. Postmortem examination of the deceased was performed, opinion of which is as under: " $1 \%$ antemortem burns stated above, are not sufficient to cause death in the ordinary course of nature. History, police record, injection marks and autopsy findings are suggestive of asphyxia death as a result of medication. Viscera / specimens / fluid are sent to the chemical examiner and bacteriologist to the Government authorities for Laboratory evaluation".

The management of hospital was contacted before proceeding. The Chief Executive of hospital explained that, General Manager has been arrested by the police and Pharmacy of the hospital has also been sealed. Moreover, doctors who handled the said minor girl have been terminated and as such no doctors were available for enquiry. Afterwards, the Board went to visit the hospital with a view to physically inspect the facilities provided in the Emergency Department for the patients. The Board on its visit to hospital confirmed availability of enough number of ventilators, but none was provided to this patient to save her life. Moreover, ambulance was also available in the hospital which too was not provided, the hospital has good resources available in enough quantity for rendering services, probably because; (1) Doctors performing CPR had confirmed death of patient but did not disclose it to her parents, (2) No body accompanied the patient to the other hospital and the parents were asked to take their critically unwell child to another hospital without a referral and without help, (3) Treatment file was not handed over to the father on the same day and perhaps notes were added later on, (4) Apparently a discharge ticket was subsequently prepared not showing any complications or death. The board agrees with the cause of death declared by postmortem examination report. The board concluded from the above, it is evident that the patient died due to criminal professional negligence / wrong treatment. The patient came to hospital and the responsibility of any negligence of any of the employees has to be shared equally by the management of hospital.

The main medication prescribed and administered during the treatment of patient were the Xylocain Gel (Local anesthetic), Deramzin ointment (Silver Sulphadiazine), Brufen Syrup (Ibuprofen), Phenergon Syrup (Promethazine), injection Dormicum (Midazolam) given $2.5 \mathrm{mg}$ and then amended to $2.0 \mathrm{mg}$ and injection Pavulon (Pancuronium bromide).
Xylocaine is an anesthetic used on the skin to relieve itching and pain associated with various skin disorders such as insect bites, burns, scrapes, plant poisonings, hemorrhoids, urinary tract procedures or the placement of endotracheal tubes. Some forms of Xylocaine are used during certain procedures to reduce pain (77 Canadapharmacy.com, 2010). It works by preventing nerves from transmitting painful impulses to the brain (Drug Information Online, 2010). Dermazine ointment (Silver Sulphadiazine) is a topical anti-infective agent with the antibacterial properties of both silver ion and sulfadiazine. Both free silver and the sulfonamide moiety may exert activity, Silver Sulphadiazine is used to prevent and treat infections of wounds caused by second- and third-degree burns. Brufen or Ibuprofen (iso-butylpropanoic-phenolic acid) is a non-steroidal antiinflammatory drug (NSAID) available under various other trademarks; Nurofen, Advil, and Motrin. It is a 'core' medicine in the World Health Organization's "essential drugs list", which is a list of minimum medical needs for a basic health care system (WHO Model List of Essential Medicines, 2010). Phenergon (Promethazine) belong to the class of chlorpromazine (Thorazine) and trifluoperazine (Stelazine). However, unlike the other drugs in this class, promethazine is not used as an antipsychotic. It used as an anti-histamine, sedative, and antiemetic (anti-nausea). It is used as a sedative because it causes drowsiness as a side effect. The FDA approved promethazine in 1951 (William and Melissa, 2010). Dormicum (Midazolam) is a short-acting benzodiazepine with an elimination half-life of one to four hours (Barash at el., 2009)); however, in the elderly, as well as young children and adolescents, the elimination half life is longer (Rosenbaum et al., 2009). Midazolam is metabolized into an active metabolite alpha1hydroxymidazolam. Age related deficits and renal or liver status affect the pharmacokinetic factors of midazolam and its active metabolite (Spina and Ensom, 2007). It is poorly absorbed orally and metabolised by cytochrome P450 (CYP) enzymes and by glucuronide conjugation. Pharmacological properties include; sedation, hypnotic, anxiety, anterograde amnesia, muscle relaxation and anti-convulsion (Riss, et al., 2008).

The most important drug of this case report is pancuronium (Pavulon) is a muscle relaxant with various purposes. It is the second of the three drugs administered during a lethal injection in the United States (BBC article on lethal injection, 2004). Pancuronium is used with general anesthesia in surgery for muscle relaxation and as an aid to intubation or ventilation. It does not have sedative or analgesic effects. In Belgium and the Netherlands, pancuronium is recommended in the protocol for euthanasia after administration of sodium thiopental to induce coma, pancuronium in order to stop breathing (Royal Dutch Society for the Advancement of Pharmacy, 1994). It was also used in Efren Saldivar's (an American serial killer who murdered patients while 
working as a respiratory therapist) killing spree (Katherine, 2010).

Pancuronium is a typical non-depolarizing curaremimetic muscle relaxant. It acts as a competitive acetylcholine antagonist on neuromuscular junctions, displacing acetylcholine from its post-synaptic nicotinic acetylcholine receptors. The initial dose of Pavulon for neuromuscular blockade is $0.06-0.1 \mathrm{mg} / \mathrm{kg}$ or $0.05 \mathrm{mg} / \mathrm{kg}$ after initial dose of succinylcholine for intubation. The maintenance dose is $0.01 \mathrm{mg} / \mathrm{kg} \mathrm{60-100} \mathrm{min} \mathrm{after} \mathrm{initial}$ dose and then $0.01 \mathrm{mg} / \mathrm{kg}$ every $25-60 \mathrm{~min}$. Neuromuscular blockade in the ICU is $0.05-0.1 \mathrm{mg} / \mathrm{kg}$ bolus followed by $0.8-1.7 \mathrm{mcg} / \mathrm{kg} / \mathrm{min}$ once initial recovery from bolus observed or $0.1-0.2 \mathrm{mg} / \mathrm{kg}$ every 1 to $3 \mathrm{~h}$ (GlobalRPh.com, 2010). The ED95 (dose causing a $95 \%$ reduction in muscle activity) is only $60 \mu \mathrm{g} / \mathrm{kg}$ body weight administered intravenously. Muscle relaxation suitable for intubation sets in about 90 to $120 \mathrm{~s}$ after administration of the drug. Full muscle paralysis for major surgery is achieved about 2 to 4 min after application. Clinical effects last for about $100 \mathrm{~min}$. The time needed for full (over $90 \%$ muscle activity) recovery after single administration is about 120 to 180 min in healthy adults, but can be protracted to more hours in poor health subjects and when concomitantly administered with other long-acting anesthetics BBC News (2010). The patient under discussion attained the toxicity and her heart beat and respiration gradually diminished.

Therapeutical findings of the report under discussion are in line with Wysowski (2007), who reported that the deaths due to overdoses are the most prominent cause of drug-related mortality in death certificate data. He concluded that the certain drugs classes, especially the opioids, psychoactive, anticoagulants and antibacterials are associated with large and increasing numbers of deaths. The preventive strategies should be considered while administering this drug.

Madea et al. (2009) reported a retrospective multicentre study on medical malpractice cases with lethal outcome, drug related cases. In 232 cases a causal connection between drug therapy and death could be approved. However, within the legal context only in 70 cases a medication error was approved which was in 42 cases causal for death and 28 are not. Concerning the frequency of adverse drug events (ADE) the medication errors are underreported in all data sources on medical malpractice; this seems to be due to the fact that, even doctors and attending physicians rarely recognize an ADE.

In another way, clinical report under discussion also demands the elaboration of certain clinical and pharmaceutical issues to figure out the scientific reasons, permissible matters and professional concerns. As; the pharmaco-therapeutical requirements are not been fulfilled. The pharmaceutical services did not meet the standard of hospital pharmacy practice. The physician got the injection directly, the pharmacy staff issued it without proper procedure of pharmaceutical practiced. The physician had to provide his formal informations (name, license number, prescription detail etc) along with the patient's data (medical history, social background, personal profile etc). Moreover; scientifically the prescription is considered as health-care program to implement and governs the plan of care for an individual patient (Belknap et al., 2008). The procedure of prescription and dispensing is applied to avoid ambiguities or misinterpretation in clinical practice (Teichman and Caffee, 2002). In this case report the standard procedures have been violated. The chance of this wrong medication was possible to control if the prescription be reviewed properly, the clinical plan evaluated correctly and pharmaceutical services provided with all of their formalities.

Therapeutic drug monitoring and pharmacovigilance are safety valves in clinical practice. The blood levels of potent drugs with a narrow therapeutic index are measured periodically to assure the safety of life (Marshall and Bangert, 2008). These are useful constraints employed to minimize the therapeutical complications; detection, assessment, understanding and prevention of adverse effects of medicines (WHO, 2002). FIP (2010) has emphasized the six major elements to contribute to an overall strategic thrust of the board of pharmacy practice in hospital pharmacy section (http://www.fip.org/hospital_pharmacy). The six major elements are including the partnership with patients, enhancing pharmacy practice, better financial models, evidence-based practices, assuring competency and sufficient workforce. These factors designed with the collaboration of World Health Organization, UNESCO, World Health Professions Alliance, Regional Pharmaceutical Forums and all other partners (FIP, 2010). The patient's critics, complaint, views or resentment are another important feature of therapeutical practice. Which are the expressions of displeasure or grievance (Lee, 2010).

In view of the aforementioned facts and circumstances, the inquiry board suggested to the honorable Chief Justice of the High Court, to take serious action on account of this negligence. But they have totally ignored the poor channel through which this injection was provided without proper procedure. The government authorities and judiciary should have to consider the pharmaceutical services, drug rules, therapeutical drug monitoring, phramcovigilance, prescription review and clinical evaluation. The clinical setup of hospital pharmacy of third world countries need the bio-safety, drug informations, aseptic dispensary as accomplished in the developed part of the world. We must have to build up awareness about the pharmaceutical services. The inquiry board have not written even a single word to place a check between the physician and patient to make sure of the correct medication, right dose, proper route in exact time. It is not single death but a representation of 
so many casualties occurring every day because of the wrong medications. It needs a collective effort of society, judiciary and leadership to change the rules, system, policies and strategies to assure the safety of precious live of innocent people.

\section{RECOMMENDATIONS}

1. Enforcement of drugs rules to assure the standard drug monitoring system including prescription review, dose calculation and therapeutical evaluation.

2. Examination and update of the physicians for their executed procedures, scientific techniques, chemotherapy protocols, professional skills and clinical expertise.

3. Maintenance of the threat of lawsuit is an excellent reason of quality services. If may become more effective if helped by insurance coverage. The insurer should be notified. Notice is a requirement of all policies and it may authorize a quick settlement.

4. Make sure the availability of clinical pharmaceutical services round the clock. The pharmacist must have to collect the medical, social, personal and professional data of patient to figure out any possible potential health hazard.

5. Implementation of the six major contributing elements of hospital pharmacy section designed by international pharmaceutical federation (FIP) with the collaboration of World Health Organization, UNESCO, World Health Professions Alliance, Regional Pharmaceutical Forums and all other partners (http://www.fip.org/hospital_pharmacy).

6 . The patient and/guardian should be briefed about the illness, treatment protocol, and possible outcomes if professional ethics have no restriction to do so. It may also help to instigate the procedure to uncover the patient's complaints.

7. Development of a process of handling the patient complaints; that may help to create a long-term effect of reducing malpractice risks. Most patients are willing to forgive occasional annoyances or disappointments if they perceive that medical professional and the office staff care about their needs and are trying to satisfy them. Therefore; the verbal, non-written policy and unofficial procedure may help to cope with the situation and develop professional understanding.

8. The physician should try to keep the patients well treated and happy. He should be vigilant about the inevitable complaints and strategy to tackle. Furthermore; in staff meetings the problems and complaints should be discussed for future benefit.

9. Any kind of patient's letter, phone call, e-mail or text message should be bothered and invite for a free consultation. He should be replied promptly with an expression of taking good care of his case that will mitigate the grumbles and improve level of satisfaction.
10. The patient should be addressed directly in case of clinical grievance. The physician has to involve him more seriously to assure the quality of care concerns. The bad result is not necessarily the result of any human failures/ error.

11. The problems related to the irregular visit, nonprofessional behavior, inadequate diagnostic facilities and non healthy condition in the hospital setting can only be resolved by designing certain rules and regulations.

\section{ACKNOWLEDGEMENT}

The author wishes to acknowledge Mr. Wajahat Latif, Director, University of Lahore (Islamabad Campus), Islamabad, Pakistan.

\section{REFERENCES}

Barash PG, Cullen BF, Stoelting RK, Cahalan MD (2009). Clinical Anesthesia $(6$ ed.). Lippincott Williams Wilkins. 588. ISBN 978-07817-8763-5 YI9P2DLe9UC\&pg=PA588

BBC News (2010). Doctor felt babies were suffering. BBC News. 200707-09. Retrieved 2010-05-21.

BBC article on lethal injection (2004). Small panel lists the chemicals usedhttp://news.bbc.co.uk/2/hi/americas/7350982.stm

Belknap SM, Moore H, Lanzotti SA, Yarnold PR, Getz M (2008). Application of software design principles and debugging methods to an analgesia prescription reduces risk of severe injury from medical use of opioids". Clin. Pharmacol. Therapeutics, 84(3): 385-392.

CBA (2010). The Canadian Bar Association, British Colombia Branch, 10th Floor, 845 Cambie Street, Vancouver, BC V6B 5T3 http://www.cba.org/bc/public_media/health/420.aspx

77Canadapharmacy.com (2010), Xylocaine Ordering and Information Page, 7-1421 St. James Street, Winnipeg, MB R3H OY9 Canada, customerservice@77canadapharmacy.com, http://www.77canadianpharmacy.com/buy-Xylocaine-ointment.php

Drug information Online, (2010). Drugs.com, Data sources include Micromedex ${ }^{\mathrm{TM}}$, Cerner Multum ${ }^{\mathrm{TM}}$, Wolters Kluwer ${ }^{\mathrm{TM}}$ and others. $\begin{array}{llll}\text { Copyright 2000-2010 Drugs.com. } & \text { (c) }\end{array}$ http://www.drugs.com/cons/xylocaine-topical.html

FIP (International Pharmaceutical Federation) (2010). Hospital Pharmacy Section, Section officers, The Future of Hospital Pharmacy - Basel Conference, Statutes, Hospital Pharmacy Section Annual Report 2009-2010, Andries Bickerweg 52517 JP The Hague The Netherlands http://www.fip.org/hospital_pharmacy

GlobalRPh.com (2010). Clinicians ultimate Reference, University of Florida, Gainesville, Florida USA http://www.globalrph.com/pancuronium_renal.htm

Katherine R (2010). Dark Rumors, Tru crime library Criminal mind and methods, 2010 Turner Broadcasting System, Inc. A Time Warner Company;

http://www.trutv.com/library/crime/notorious_murders/angels/efren_sa Idivar $/ 1 . \mathrm{html}$ ?sect=9

Lee J, Johnson Esq (2010). Malpractice Dangers in Patient Complaints, Attorney with Johnson and Associates, Mt. Kisco, New York, Medscape, LLC, 370 Seventh Avenue, Suite 1101, New York, NY 100013967http://www.medscape.com/viewarticle/725001?src=mp\&s pon=17\&uac $=145767 \mathrm{CJ}$

Madea B, Musshoff F, Preuss J (2009). Medical negligence in drug associated deaths. Institute of Forensic Medicine, University of Bonn, Stiftsplatz 12, 53111 Bonn, Germany. Forensic Sci. Int. 2009 Sep 10; 190(1-3):67-73. Epub 2009 Jun 26.

Marshall WJ, Bangert SK (2008). Clinical Chemistry, 6th Edition. Edinburgh, London: Mosby Elsevier. 
Medical

Malpractice

(2010). http://www.lawmedmal.ca/medical malpractice_law.htm

Riss J, Cloyd J, Gates J, Collins S (2008). "Benzodiazepines in epilepsy: pharmacology and pharmacokinetics.". Acta Neurol. Scand., 118(2): 69-86. doi:10.1111/j.1600-0404.2008.01004.x. PMID 18384456.

Rosenbaum A, Kain ZN, Larsson P, Lönnqvist PA, Wolf AR (2009). "The place of premedication in pediatric practice" (PDF). Paediatr.

Anaesth., 19(9): 817-28. doi:10.1111/j.1460-9592.2009.03114.x. PMID 19691689.

Spina SP, Ensom MH (2007). "Clinical pharmacokinetic monitoring of midazolam in critically ill patients.". Pharmacotherapy, 27(3): 389-98. doi:10.1592/phco.27.3.389. PMID 17316150.

Teichman PG, Caffee AE (2002). "Prescription writing to maximize patient safety" Fam. Pract. Manage., 9(7): 27-30. PMID 12221761. http://www.aafp.org/fpm/2002/0700/p27.pdf.

William C, Shiel MC (2010). Webster's New World Medical Dictionary First, Second and Third Editions (May, 2008) John Wiley \& Sons, Inc.; ISBN-10: 0470189282. MedicineNet.com, (2010), http://www.medicinenet.com/promethazine/article.htm
WHO Model List of Essential Medicines (2010). World Health Organization. March 2005 http://whqlibdoc.who.int/hq/2005/a87017_eng.pdf. Retrieved 200603-12.

WHO (2002). The Importance of Pharmacovigilance, World Health Organization, Avenue Appia 201211 Geneva 27 Switzerland.

Wysowski DK (2007). Surveillance of prescription drug-related mortality using death certificate data. Division of Drug Risk Evaluation, Food and Drug Administration, Silver Spring, Maryland 20993, USA. Drug Saf.( 2007), 30(6): 533-340. 